\title{
Estórias Gerais e Primeiras Estórias: o sertão em imagens, o sertão em palavras. Uma proposta de leitura para a Educação Básica
}

Carolina Valada Becker*

\begin{abstract}
Não, não te recomendo a leitura de Joaquim Manuel de Macedo ou de José de Alencar. Que ideia foi essa do teu professor?

Mario Quintana
\end{abstract}

Resumo: Trabalhar as obras de Guimarães Rosa, no Ensino Médio, sem dúvida, é um desafio, pois a linguagem rosiana e seu universo temático podem distanciar leitores ainda em formação. Tendo em vista essas especificidades estéticas, proponho um trabalho intertextual para apresentar Guimarães aos alunos. Trata-se da leitura de duas obras: a graphic novel "Estórias Gerais", de Wellington Srbek (roteiro) e Flavio Colin (ilustrações), cujo conteúdo é autoral e revisita, assim como Rosa, o sertão e sua cultura; e o livro de contos "Primeiras Estórias", de Guimarães Rosa. Pretende-se, por meio do conceito de Letramento Literário, aproximar os alunos do ato de ler, partindo de um gênero híbrido - uma graphic novel -, para, em seguida, chegar à obra canônica de Guimarães.

Palavras-chave: Contos; Graphic novel; Projeto de leitura; Guimarães Rosa.

* Graduada em Letras pela UFRGS e mestranda em Teoria da Literatura pela PUCRS.

E-mail: carol.valada@hotmail.com 


\begin{abstract}
To deal with the works of Guimarães Rosa in High School is undoubtedly a challenge, because the language of the author and his thematic universe may distance young readers still in formation. Having these aesthetic specificities in mind, I propose an intertextual work in order to present Guimarães to the students. It includes two readings: the graphic novel Estórias Gerais by Wellington Srbek (writer) and Flavio Colin (illustration), which has an authentic content that revisits, just like Rosa, the sertão region and its culture; and the short story book Primeiras Estórias by Guimarães Rosa. Using the Literary Literacy concept, the intention is to bring students closer to the act of reading, starting with a hybrid genre - a graphic novel and after that, reaching Guimarães canonical work.
\end{abstract}

Keywords: Short stories; Graphic novel; Reading project; Guimarães Rosa.

\title{
Introdução
}

O sertão é um mundo, explica Riobaldo, personagem-narrador do romance "Grande Sertão: Veredas", de Guimarães Rosa, a seu interlocutor silenciado e, consequentemente, a seu leitor. Em uma sala de Ensino Médio, fica a dúvida: como apresentar o sertão aos alunos? Como mediar a relação dos estudantes com o universo e a obra de Guimarães Rosa? A dúvida materializa-se porque, em geral, a leitura do romance Grande Sertão: Veredas é - atrevo-me a dizer - impossível de ser aplicada em sala de aula1. Por outro lado, os contos do autor, presentes no livro "Primeiras Estórias", podem ser uma excelente maneira de iniciação ao universo sertanejo - sua jagunçagem, sua linguagem - e à poética rosiana.

1 Não digo, de modo algum, que não existam alunos, na Educação Básica, capacitados, letrados literariamente, para executar tal leitura. Entretanto, devido à dimensão estilística e à organização narrativa do livro, o ato de ler torna-se, sem dúvida, uma ação muitíssimo exigente e aplicá-la em sala de aula exigiria um tempo muito expressivo. 
Mesmo diante da leitura de um gênero mais conciso como o conto, o aluno se digladia com as palavras e a temática de Rosa, com sua semântica e sua sintaxe. Apresentar Guimarães Rosa a um leitor inexperiente ou ainda em desenvolvimento pode ser uma experiência traumática. Sabemos, como professores da Educação Básica, que toda leitura realizada em sala de aula merece mediação. Então me pergunto: como, afinal, mediar a leitura de Guimarães Rosa?

Partindo dessa inquietação, este artigo ensaia uma proposta de leitura: proponho um planejamento de atividades, um projeto, que prioriza o ato de ler e a fruição, tentando apropriar-se do conceito de letramento literário e assumindo como objetivo um ensino literário nas escolas cujo mote seja a literatura comparada. Para tanto, duas obras foram selecionadas: uma graphic novel intitulada "Estórias Gerais", com roteiro de Wellington Srbek e desenhos de Flavio Colin; e um livro de contos, "Primeiras Estórias”, de João Guimarães Rosa.

\section{Por que Guimarães Rosa? Por que ler?}

Um dos primeiros questionamentos dos alunos, quando convidados (ou obrigados, por meio de leituras mensais ou trimestrais, as quais serão avaliadas) a ler uma obra literária na disciplina curricular "Literatura" é este: por que preciso ler este autor e esta obra²? A dúvida é legítima, uma vez que eles, em geral, não escolheram a obra a ser lida e, mais comum ainda, são levados a ler clássicos da literatura brasileira, os quais, inúmeras

2 Por vezes, o aluno questiona o mais básico dessa atividade: por que ele precisa ler? Nessa circuntância, essencial é que o professor esteja convicto e saiba por que, afinal, a leitura, especificamente a leitura literária, é importante. Um argumento nos dá Vincent Jouve: "Ler, pois, é uma viagem, uma entrada insólita em outra dimensão que, na maioria das vezes, enriquece a experiência: o leitor que, num primeiro momento deixa a realidade para o universo fictício, num segundo tempo volta ao real, nutrido de ficção” (JOUVE, 2002, p. 109); outras razões, defesas do ato de ler, encontramos nos escritos de Antonio Candido; para o crítico, a literatura é essencial pois humaniza o ser humano (CANDIDO, 1988). 
vezes, são muito distantes do universo do aluno. Os professores de Literatura, por sua vez, podem ensaiar diversas respostas para seus alunos e, certamente, a construção do cânone será uma explicação. Na verdade, o professor deve questionar-se: afinal, por que e com quais objetivos ensinamos o que ensinamos?

Se seguirmos o argumento do cânone, diremos que, na história da literatura, alguns autores e algumas obras são tão importantes que nós, na contemporaneidade, os lemos. Compreenderão a resposta apenas os alunos que tiverem conhecimento do conceito de sistema literário. $\mathrm{O}$ argumento é legítimo, porém não exclui um trabalho didático e literário com obras contemporâneas e, principalmente, um trabalho intertextual, a partir do qual obras canônicas possam estar em diálogo com criações contemporâneas.

Não questionarei, aqui, se devemos ou não trabalhar Guimarães Rosa em sala de aula e o porquê disso. A priori, ele é um autor que deve ser conhecido pelos alunos, uma vez que desvenda e recria as ideias e as identidades presentes no regional, transformando-as em universal. Parto da ideia, portanto, de que sim, Guimarães Rosa estará nas salas de aula. Portanto, o questionamento torna-se outro: como apresentá-lo aos alunos?

Essa certeza sobre a importância de Guimarães leva-nos a outro aspecto. $\mathrm{O}$ ato de ler deve ser prioridade, devemos fruir as palavras de Guimarães, pois apenas assim o aluno compreenderá, de fato, a dimensão daquela construção estética. Insuficiente, portanto, é dizer aos alunos que Guimarães Rosa existiu e que sua criação literária é única; é preciso ler a obra e não conhecer apenas a historiografia. Segundo Afrânio Coutinho, duas posturas têm aparecido em nosso ensino de Literatura:

A abordagem histórica leva-nos a reduzir o ensino da Literatura ao da História literária, ou seja, à exposição da ambiência histórica, social ou econômica, que teriam condicionado a produção das obras, e da vida dos autores nos seus pormenores exteriores e na sua psicologia. [...] E ensino da Literatura, consoante esse critério, passou a reduzir-se ao estudo histórico das literaturas, isto é, ao conhecimento do meio social, político, histórico, econômico e da vida dos escritores, confundindo assim o fato histórico e o fato literário, que são as obras elas próprias. 
O aprendizado reduzia-se, em última análise, à memorização de nomes, títulos e datas, ou alguns pitorescos fatos biográficos (COUTINHO, 2008, p. 25).

Nas salas de aula da Educação Básica, principalmente no Ensino Médio, esquecemos de tratar a literatura como arte, a arte da palavra, a arte da representação. Sem dúvida, noções de sistema literário, como mencionei acima, e de história da literatura são importantes, mas de modo algum substituem a fruição da obra. Apenas essa percepção, o ato de experienciar a literatura ${ }^{3}$, pode recuperar o seu caráter artístico.

Uma comparação é interessante: os alunos, em geral, não duvidam de que o cinema seja uma arte e conseguem externalizar opiniões tanto sobre sua temática quanto sobre sua construção narrativa. Em oposição, quando se trata de um conto, romance ou poesia, isso se torna um desafio. Essa constatação demonstra que continuamos a tratar a literatura como um objeto instalado em uma torre de marfim, isto é, distanciada da vida real. Para o aluno, em geral, o cinema está inserido em seu dia a dia e, por isso, não distanciado.

Volto às ideias de Afrânio Coutinho. O crítico sugere substituirmos esse ensino engessado e historiográfico por um ensino genológico, o qual prioriza o conhecimento dos gêneros literários e, assim, o contato com as obras e com a leitura. $\mathrm{O}$ método consiste, nas palavras de Afrânio, "em colocar o educando em contato direto, desde o início, com o texto literário, através dos gêneros (COUTINHO, 2008, p. 27).

Desse modo, inevitavelmente, o aluno conhecerá elementos inerentes à forma literária e o fará por meio da leitura. Depois de ler uma peça, um romance, um conto, uma crônica, um poema, o estudante poderá compreender o que são esses gêneros e suas especificidades.

3 Essa discussão está em pauta desde a década de 80, principalmente com escritos de Regina Zilberman, como o artigo "A leitura na escola": "A proposta de que a leitura seja reintroduzida na sala de aula significa o resgate de sua função primordial, buscando sobretudo a recuperação do contato do aluno com a obra de ficção" (ZILBERMAN, 1993, p, 21). 
Somam-se a essas reflexões a ideia de projeto de leitura ou programa de leitura. Não basta dizer ao aluno, 'leia'; precisamos, como professores, mediar essa relação. As propostas de Rildo Cosson, nesse caso, são importantes: ele parte do conceito de Letramento $^{4}$ - em geral, utilizado na área da linguística - e o desloca para a literatura. Em síntese, ele sugere: “[...] é fundamental que se coloque como centro das práticas literárias na escola a leitura efetiva dos textos, e não as informações das disciplinas que ajudam a construir essas leituras, tais como a crítica, a teoria ou a história literária” (COSSON, 2011, p. 21).

Ler, no entanto, não é um ato pacífico e simplista; o ato de ler é uma negociação e não uma "simples viagem ao imaginário", como muitas campanhas publicitárias, a favor da leitura, propagam. Ler é construir sentido, é desacomodar-se e, portanto, é trabalho árduo, mas que, ainda assim, pode ser um momento de entretenimento - aspecto para muitos não leitores inimaginável.

A leitura literária - assim como a leitura de diversos gêneros textuais presentes no cotidiano (reportagem, notícia, resenha) - deve proporcionar ao aluno, além da observação artística, criticidade. Para Afrânio Coutinho, isso nos remete a uma leitura expressiva, interpretativa e dialogada (COUTINHO, 2008, p. 27). Esse ato de ler é, na verdade, um caminho para a análise literária, cujo cerne prevê a criticidade, uma vez que o aluno deve conhecer o gênero e analisá-lo estruturalmente e observar o estilo do autor, tecendo juízos de valor baseados em uma vivência de leitura. Um explicação mais pontual faz-se necessário: sem dúvida, o conceito de história da literatura, bem como o conhecimento de que existem a crítica e a teoria literária são indispensáveis, afinal, compõem o sistema literário. Entretanto, esse campo de conhecimento deve, a meu ver, ser agregado à sala em união à leitura. Em outras palavras, o aluno pode cumprir a função de crítico literário, bem como pode teorizar a partir de

4 Magda Soares define letramento como um "estado ou condição de quem não apenas sabe ler e escrever, mas cultiva e exerce as práticas sociais que usam a escrita” (SOARES, 2004). 
sua leitura, de suas interpretações. A esse momento mais pessoal de construção de sentido, nós, professores, devemos agregar o campo teórico e as análises cristalizadas da crítica. Trata-se, na verdade, de repensar como organizamos nossa prática de ensino: pedimos a nossos alunos que reproduzam as ideias de teóricos e críticos da literatura, sem incitar a sua leitura crítica, ou permitimos que ambas as vozes tenham espaço e força? Dar voz ao aluno e às suas valorações literárias será possível, apenas, se ele, de fato, tornar-se um leitor.

\section{Ler quadrinhos e ler prosa: o letramento literário e suas etapas}

Até aqui, tentei discutir o ensino de literatura, sua proposta recorrente e algumas novas perspectivas. Reitero: o ensino de literatura pode priorizar o ato de ler, e não o ensino historiográfico; os trabalhos em sala de aula podem partir da conceituação de gênero literário e, sempre que possível, constituir um projeto de leitura, ou seja, uma produção em etapas, cujos saberes venham do ato de ler.

No plano das ideias, essa é uma boa proposta. Entretanto, todos aqueles que já adentraram uma sala de aula sabem o quanto a docência é desafiadora. Por isso, as atividades devem ser bem elaboradas, o professor deve ter consciência de seus objetivos. Se o professor não estiver convicto do que faz, o aluno perceberá. Nesse sentido, a estrutura do projeto a ser aplicado é muito importante. A primeira postura teórica a ser assumida refere-se à conceituação de literatura comparada. Não se busca, evidentemente, fontes e influências (tendência já abandonada pela teoria da literatura), mas sim elementos textuais, temáticos e estruturais que dialoguem, suscitando reflexões.

Propor um ensino de literatura que seja baseado em literatura comparada - uma das tendências teóricas mais pululantes dos últimos anos - é demonstrar aos estudantes a presença da 
literatura no dia a dia e o dinamismo da criação artística. Podemos ler um poema ou um conto e contrastá-lo com um filme, uma canção, uma obra de arte. Uma educação literária comparada prevê a intertextualidade materializada. Para Julia Kristeva, na canônica obra 'Semanálise', a estrutura literária é uma elaboração sempre em relação a outra; ela referencia Bakthin e prossegue:

Esta dinamização do estruturalismo só é possível a partir de uma concepção, segundo a qual a "palavra literária" não é um ponto (um sentido fixo), mas um cruzamento de superfícies textuais, um diálogo de diversas escrituras: do escritor, do destinatário (ou da personagem), do contexto cultural atual ou anterior (KRISTEVA, 1974, p. 62).

Na proposta deste artigo, o diálogo estabelecido é genológico: de um lado, o sertão de Guimarãesa Rosa, canônico e em prosa; de outro, o sertão de Wellington Srbek e Flavio Colin, em certa medida, um gênero marginalizado, a história em quadrinhos $^{5}$, mas que na sua estrutura compartilha elementos estruturais narrativos, como personagem, tempo, espaço, narrador (ainda que este possa ou não estar presente), algo que se aproxima à definição de arquigênero, proposta por Gerád Genette, para quem, "em suma, todo o gênero pode conter sempre gêneros vários” (GENETTE, 1990, p. 80).

O projeto proposto busca, pois, exatamente o "cruzamento de superfícies textuais” explicitado por Kristeva. Por meio do lugar sertão temos um processo intertextual entre as obras selecionadas. Sendo assim, é esta a motivação a ser levada aos alunos: desvendar o que é o sertão e o que é o jagunço. A ideia é partir da graphic novel "Estórias Gerais", a qual dialoga com o universo temático de Guimarães, para, então, chegar aos contos de "Primeiras Estórias".

Por que a HQ primeiramente? O que norteia essa ordem de leitura é um palpite: creio que os alunos, devido ao caráter

5 Podemos nomear os quadrinhos, neste gênero específico que estou trabalhando, de graphic novel, narrativa gráfica ou narrativa sequencial. Essa conceituação pode ser encontrada na obra "Narrativas gráficas: princípios e práticas da lenda dos quadrinhos”, de Will Eisner (São Paulo: Devir, 2008). 
visual da sociedade, estejam mais familiarizados com as imagens, logo, pressuponho que sua identificação com as histórias em quadrinhos seria mais rápida. Em outras palavras, por se tratar de um gênero híbrido, a graphic novel é um convite à leitura, uma vez que o aluno pode considerá-la mais próxima ao seu mundo, aos seus conhecimentos. Além disso, as imagens da HQ são uma maneira de apresentar o sertão, o qual nem sempre está no imaginário dos alunos.

A metodologia deste projeto de leitura segue as etapas propostas por Rildo Cosson, no livro já citado "Letramento Literário", que estabelece dois eixos de ação. O primeiro, chamado "Sequência metodológica básica", tem três etapas: a) Antecipação - especificar os objetivos do trabalho e utilizar algo que "motive" os alunos a ler; b) Decifração - a leitura em si, a decodificação; e c) Interpretação - algo além da decodificação, o ato de criar relaçôes com o texto lido. Segundo Cosson (2011, p. 41), "interpretar é dialogar com o texto tendo como limite o contexto".

Soma-se à etapa descrita o que Rildo Cosson chama de "sequência expandida", a qual, segundo sua proposta, é mais apropriada para o Ensino Médio, pois desdobra o eixo anterior. Vejamos as etapas que a compõem: a) Motivação; b) Introdução; c) Leitura; d) Primeira interpretação; e) Contextualização - a qual se desdobra em algumas etapas; f) Segunda interpretação; e, por fim, g) Expansão. Vejamos uma tabela criada a partir dos conceitos de Rildo Cosson. Nela, temos a explicação das etapas; em seguida, discutirei cada uma dessas etapas, utilzando como exemplos as duas obras selecionadas, a HQ e os contos de Guimarães.

Tabela 1: etapas da "Sequência Expandida".

\begin{tabular}{|l|l|}
\hline a) motivação & Antecipar o que será lido \\
\hline b) introdução & $\begin{array}{l}\text { Localizar o autor e a obra no campo } \\
\text { literário e histórico }\end{array}$ \\
\hline c) leitura & Ler, ou seja, decodificar a obra \\
\hline d) primeira interpretação & $\begin{array}{l}\text { Interpretar de forma livre a obra; im- } \\
\text { pressões de leitura }\end{array}$ \\
\hline
\end{tabular}




\begin{tabular}{|l|l|}
\hline e) contextualização & $\begin{array}{l}\text { Trazer informações sobre a obra em } \\
\text { diversos níveis, como a história, a teoria } \\
\text { literária, o estilo. }\end{array}$ \\
\hline f) segunda interpretação & $\begin{array}{l}\text { Somar saberes: a primeira interpretação } \\
\text { e a contextualização }\end{array}$ \\
\hline g) expansão & $\begin{array}{l}\text { Estabelecer relaçôes textuais, trabalho de } \\
\text { intertextualidade }\end{array}$ \\
\hline
\end{tabular}

Fonte: tabela elaborada pela autora.

O item "motivação" (ato de antecipar o que será lido) pode ser elaborado de forma sintética, porém, ele é essencial, pois pode provocar a curiosidade dos alunos. Uma proposta interessante é levar outros gêneros textuais para a sala de aula, como uma resenha das obras a serem trabalhadas; um documentário sobre o sertão, sobre Guimarães Rosa ou sobre quadrinhos também pode ser utilizado; algumas imagens, principalmente nesta proposta cujo mote é o sertão, podem ser interessantes. Por fim, a proposta mais simples: selecionar alguma imagem da HQ e algum trecho da obra de Guimarães Rosa, quem sabe até do romance "Grande Sertão: Veredas”, e, a partir dos excertos, direcionar a discussão. Por exemplo, o trecho abaixo, do romance rosiano citado:

Olhe: quando é tiro de verdade, primeiro a cachorrada pega a latir, instantaneamente - depois, então, se vai ver se deu mortos. O senhor tolere, isto é o sertão. Uns querem que não seja: que situado sertão é por os campos-gerais a fora a dentro, eles dizem, fim de rumo, terras altas, demais do Urucúia. [...] Lugar sertão se divulga: é onde os pastos carecem de fechos; onde um pode torar dez, quinze léguas, sem topar com casa de morador; e onde criminoso vive seu cristo-jesus, arreado do arrocho de autoridade. [...] O sertão está em toda a parte. [...] Sertão. O senhor sabe: sertão é onde manda quem é forte, com as astúcias. Deus mesmo, quando vier, que venha armado! (ROSA, 2001, p. 23, 35)

A partir dessa definição de sertão, pode-se iniciar os trabalhos, perguntando aos alunos - estou pensando em um terceiro ano do Ensino Médio - quais elementos identitários podem compor o sertão - além disso, por ser um trecho da obra mais 
expressiva de Guimarães, os alunos terão uma notícia sobre ela. Junto com o trecho, duas imagens da HQ "Estórias Gerais" podem ser apresentadas:

Figura 1: o sertão em imagens

(Estórias Gerais, p. 72)

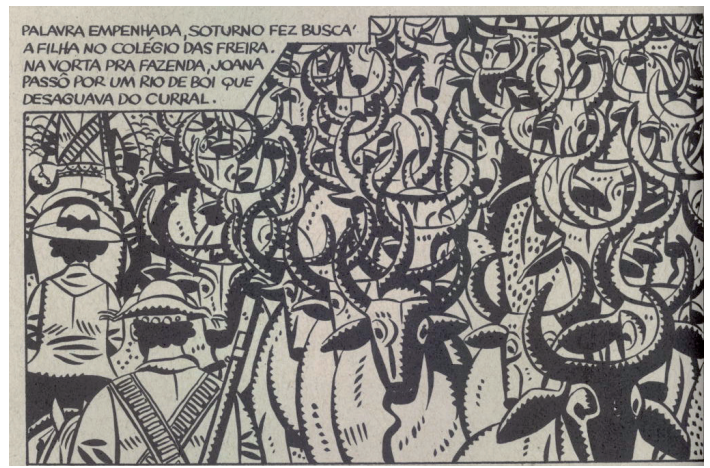

Figura 2: a violência do sertão

(Estórias Gerais, p. 139)

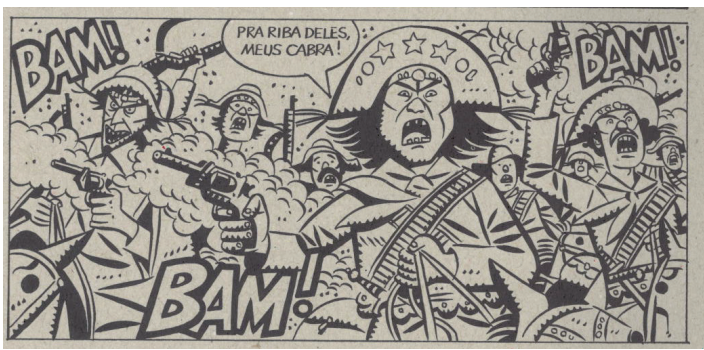

A motivação acima proposta é um meio de introduzir o projeto de leitura, tanto a obra em quadrinhos quanto os contos de Guimarães Rosa. As próximas etapas serão realizadas em momentos distintos, por isso temos propostas específicas para cada obra. Reitero que primeiramente seja realizada a leitura de 
"Estórias Gerais" e, posteriormente, de "Primeiras Estórias", como foi justificado no subitem anterior.

O item "introdução" dialoga com a historiografia, pois pressupõe a apresentação dos autores, sua localização no campo literário e histórico. Vale observar que se o item anterior, "motivação", apresentar um documentário, como foi sugerido, essa etapa também estará contemplada. Para os quadrinhos, uma reflexão sobre as relaçôes do sistema literário com o gênero graphic novel pode ser interessante, ressaltando seus aspectos narrativos, ou alguma informação mais elaborada sobre os quadrinistas escolhidos. Nos livros didáticos, certamente há referência a Guimarães Rosa e sua importância para a literatura. Além desse material, reportagens publicadas em revistas especializadas podem auxiliar, ou, ainda, trechos de críticos, como a apresentação de Paulo Rónai (Os vastos espaços), publicada na edição da Nova Fronteira do livro "Primeiras Estórias".

O tópico "leitura" é o ato de decodificar. Acredito que um roteiro básico de leitura pode ser produtivo, no qual o aluno encontre uma lista de elementos a serem observados (elementos da narrativa, como narrador, personagens, enredo, tempo, espaço) tanto na HQ quanto nos contos. Esse recurso é interessante principalmente para alunos que não cultivam o hábito da leitura literária. Para uma turma proficiente e habituada à leitura, esse roteiro pode ser dispensado.

O próximo item do letramento literário chama-se "primeira interpretação" e é essencial, pois nessa etapa os alunos falarão sobre sua experiência de leitura, suas impressóes diante da obra de arte. Trata-se de uma conversa mais leve e nesse momento podemos, sim, utilizar o "gostei ou não gostei", pois, posteriormente, elementos estruturais serão discutidos para que os leitores possam embasar seu posionamento.

O tópico seguinte, "contextualização", prevê a ação de desvendar a obra, ou seja, busca elementos que a contextualize de modo histórico e historiográfico. São estas as suas etapas: 1) contextualização teórica - as ideias de estilo de época, de escola 
literária, veiculadas pela obra; 2) contextualização histórica época da diegese ou época da publicação; 3) contextualização estilística - uso da linguagem; 4) contextualização poética - elementos de gênero, seja da $\mathrm{HQ}$, seja do conto; 5) contextualização crítica - como a crítica especializada vê a obra; 6) contextualização presentificadora - obra e suas relaçóes com a época atual. Abaixo, temos um quadro dividido em dois eixos, um para cada obra - a graphic novel e os contos.

Tabela 2: as etapas do item "Contextualização".

\begin{tabular}{|l|l|l|}
\hline & $\begin{array}{c}\text { Estórias Gerais, } \\
\text { de Wellington Srbek } \\
\text { e Flavio Colin }\end{array}$ & $\begin{array}{l}\text { Primeiras Estórias, } \\
\text { de Guimarães Rosa }\end{array}$ \\
\hline $\begin{array}{l}\text { contextualização } \\
\text { teórica }\end{array}$ & $\begin{array}{l}\text { Discussão sobre a re- } \\
\text { cepção do gênero gra- } \\
\text { phic novel no sistema } \\
\text { literário, o preconceito } \\
\text { e sua marginalização. }\end{array}$ & $\begin{array}{l}\text { Suscitar uma reflexão } \\
\text { sobre os conceitos "re- } \\
\text { gionalismo" e "univer- } \\
\text { salismo", demonstran- } \\
\text { do as características de } \\
\text { Rosa. }\end{array}$ \\
\hline $\begin{array}{l}\text { contextualização } \\
\text { histórica }\end{array}$ & $\begin{array}{l}\text { Tentar apreender a épo- } \\
\text { ca da narrativa a partir } \\
\text { de indícios textuais. }\end{array}$ & $\begin{array}{l}\text { Tentar apreender a épo- } \\
\text { ca da narrativa a partir } \\
\text { de indícios textuais. }\end{array}$ \\
\hline $\begin{array}{l}\text { contextualização } \\
\text { estilística }\end{array}$ & $\begin{array}{l}\text { Perceber o uso da va- } \\
\text { riação linguística do } \\
\text { ambiente, observando } \\
\text { a personagem principal, } \\
\text { Ulisses, um repórter, e } \\
\text { os nativos de Buritizal. }\end{array}$ & $\begin{array}{l}\text { Analisar os neologis- } \\
\text { mos e os recursos de } \\
\text { estilo presentes na obra; } \\
\text { demonstrar, em cons- } \\
\text { traste com a HQ, como } \\
\text { Guimarães transcende a } \\
\text { ideia de simples registro } \\
\text { da oralidade. }\end{array}$ \\
\hline
\end{tabular}

* Esses elementos estruturais são discutidos, por exemplo, no livro "A leitura dos quadrinhos", de Paulo Ramos (São Paulo: Contexto, 2009). 


\begin{tabular}{|l|l|l|}
\hline $\begin{array}{l}\text { contextualização } \\
\text { poética }\end{array}$ & $\begin{array}{l}\text { Elementos de gênero } \\
\text { que podem auxiliar na } \\
\text { compreensão da obra - } \\
\text { análise de imagens e de } \\
\text { cores; o "movimento" } \\
\text { das imagens". }\end{array}$ & $\begin{array}{l}\text { Elementos de gênero } \\
\text { que podem auxiliar na } \\
\text { compreensão da obra, } \\
\text { como narrador, perso- } \\
\text { nagem etc. }\end{array}$ \\
\hline $\begin{array}{l}\text { contextualização } \\
\text { crítica }\end{array}$ & $\begin{array}{l}\text { Retomar a contextu- } \\
\text { alização teórica para } \\
\text { aprofundar a discussão } \\
\text { sobre o gênero graphic } \\
\text { novel e sua relação com } \\
\text { a narratividade. }\end{array}$ & $\begin{array}{l}\text { Trazer trechos de crí- } \\
\text { ticos essenciais da lite- } \\
\text { ratura brasileira para } \\
\text { que os alunos tenham } \\
\text { ideia da importância de } \\
\text { Guimarães. }\end{array}$ \\
\hline contextualização \\
presentificadora
\end{tabular}

Fonte: tabela elaborada pela autora.

Voltamos, agora, à sequência expandida, ao segmento chamado "segunda interpretação". Nele, relacionamos os saberes impressionistas dos alunos às contextualizações tecidas.

A última etapa, nomeada "expansão", está, na verdade, intrincada em todo o projeto, pois ela prevê relações textuais, e será desenvolvida após a leitura das duas obras. Nesse momento, de modo mais intenso, a literatura comparada será utilizada, pois, além do universo temático, o sertão, o jagunço, trechos das obras serão colocados em diálogo, bem como personagens. No próximo subitem, tecerei algumas propostas dialógicas, citando alguns contos de Rosa e alguns trechos da graphic novel "Estórias Gerais". 


\section{Entre estórias e estórias - por um ensino de literatura comparada}

Um ensino de literatura, na Educação Básica, emoldurado a partir dos conceitos teóricos da literatura comparada, prevê um diálogo textual - seja estético e formal, seja temático. Portanto, essa postura tece relações. Nesta proposta, a temática "sertão" desdobra-se em outros elementos, outros itens de uma verdadeira poética dos campos gerais, espaço revisitado e recriado por Guimarães Rosa e pelos quadrinistas.

Como iniciar, então, essa leitura intertextual? Uma tentativa de definir a identidade do jagunço e a importância da jagunçagem é um excelente ponto de partida - "jagunço num é como chuva e cheia do São Francisco, que tem época certa. Jagunço vem sem aviso" (SRBEK', 2007, p. 13). Na HQ "Estórias Gerais”, muitas personagens são jagunços, como Antônio Mortalma e Manuel Grande, inimigos, violentos, sequiosos de vingança. Na narrativa, personagens têm distintas versões para explicar os motivos pelos quais Mortalma era tão violento. Cada sujeito, morador da região Buritizal, cria uma narrativa, como evidenciam as imagens abaixo. No recurso narrativo, está explícita a ideia de contação de histórias, uma vez que diferentes depoimentos estão lado a lado.

6 SRBEK, Wellington; COLIN, Flavio (ilustração). Estórias Gerais. São Paulo: Conrad, 2007. 
Figura 3: a oralidade e a forma narrativa: a versão do padre (Estórias Gerais, p. 17)

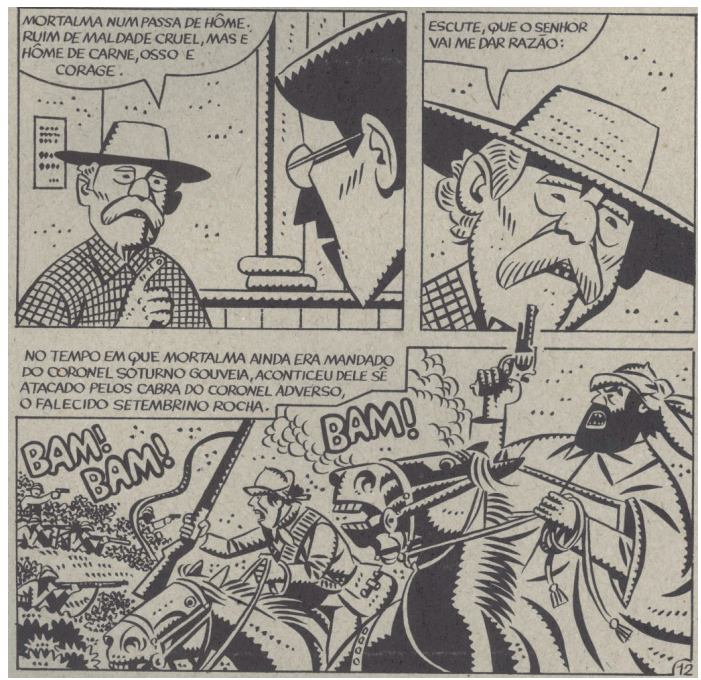

Figura 4: as muitas versões (Estórias Gerais, p. 22)

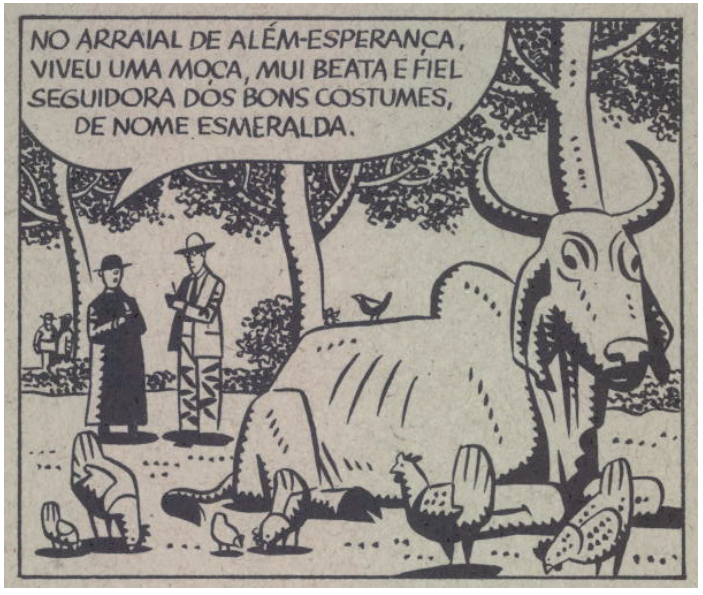


À identidade do jagunço e sua mítica origem, somamos o conceito de violência. Neste ambiente regional, os costumes seguem regras próprias, onde a lei do mais forte impera. Segundo Paulo Rónai,

[...] nos intervalos das fazendas, ocultam-se arraiais pobres, de reduzida povoação - o arraial do Breberê, o povoadinho do M'engano, o lugar chamado o Temor-de-Deus - sem quaisquer recursos de organização social. A lei do mais forte - a única existente - é exercida na fazenda sob formas paternalísticas pelo dono, assistido, para o que der e vier, dos rifles certeiros de alguns capangas; nas vilas, pelos valentões do lugar, detestados e temidos; nas escassas cidadezinhas, pela polícia lo$\mathrm{cal}$, que, para fazer-se respeitar, tem de pedir emprestado métodos da arbitrariedade (RÓNAI, 2005, p. 25)

Vale mencionar a realização da violência presente na obra "Estórias Gerais", na qual o binarismo bem e mal estão bastante definidos, por exemplo, com a não concretização da violência em "Famigerado" e "Os irmãos Dagobé”, de Guimarães Rosa.

Outro eixo temático intertextual é a identidade do louco, sujeito inadaptado ou místico: de um lado, Zé, personagem da $\mathrm{HQ}$, cuja ambição o levou a fazer um pacto com o diabo - segundo as histórias do local - e perder a lucidez, porém, ao mesmo tempo, diz verdades, o que traz um tom místico; de outro lado, em Guimarães Rosa, temos a mãe e a filha de Sorôco - no conto "Sorôco, sua mãe, sua filha", ambas loucas, e Nhinhinha e sua ingenuidade mística - no conto "A menina de lá”. 
Figura 5: personagem Zé, a identidade do louco

(Estórias Gerais, p. 117)

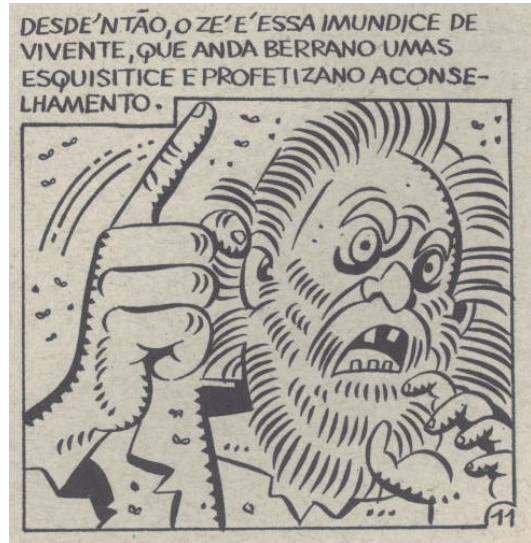

Por fim, uma última sugestão: analisar a linguagem. Em "Estórias Gerais", o registro de uma variação específica e regional resume-se a reproduzir a oralidade na escrita por meio da acentuação e união das palavras; o registro da variação linguística regional é marcado por uma escrita que reproduz a fala, isto é, na escrita, encontramos o registro da supressão dos plurais e a marcação da entonação do falar, com a acentuação. Alguns exemplos: "Num sobrô", "O único que restô foi o padre", "Ma'os de Mortalma eram feroz por demais. Mataram pra mais de vinte. Os ôtro e eu fugimo", "Foi ali mêmo".

No caso de Guimarães Rosa, sabemos que o registro dessa linguagem, na verdade, é uma transcriação. O autor apropria-se do que encontra na realidade e agrega neologismos ou modos de registrar a oralidade mais refinados, como estes, retirados dos contos de "Primeiras Estórias": "O cavaleiro esse - o oh-homemoh - com cara de nenhum amigo" (ROSA, 2005, p. 55); "O medo é a extrema ignorância em momento muito agudo. $\mathrm{O}$ medo O” (ROSA, 2005, p. 56); "Disse de não" (ROSA, 2005, p. 56); "Contra que aí estava com o fígado em más margens; pensava, pensava. Cabismeditado" (ROSA, 2005, p. 57); "Eis que eis" 
(ROSA, 2005, p. 71); "Aquilo na noite do nosso teatrinho foi de Oh" (ROSA, 2005, p. 83). A oralidade está presente e, vale ressaltar, não apenas em narradores em primeira pessoa, mas também naqueles distanciados, em terceira pessoa.

Outra reflexão indispensável refere-se à personagem Ulisses, de "Estórias Gerais". Ele é um jornalista cuja visita à cidade Buritizal objetiva retratar as pessoas que lá vivem. As palavras iniciais da graphic novel são estas, as quais, na verdade, são as anotações da personagem e evidenciam uma percepção preconceituosa:

Buritizal é um pequeno município do norte de Minas, à margem oeste do São Francisco. A despeito disso, este povoado atraiu a fúria do perigosíssimo Bandoleito que assola o sertão. [...] Por não serem agraciadas com as luzes da civilização e dos modernos tempos, tais pessoas são ainda vítimas de toda sorte de superstições e atrasos espirituais (SRBEK, 2007, p. 11, 19).

No final de "Estórias Gerais", após viver muitas peripécias no sertão e conhecer a região, Ulisses mudará sua visão:

Certamente, desconhecemos nossa própria nação. Por prepotência olhamos para ela - e apara aqueles que vivem em seus campos mais distantes - com um olhar de superioridade, de estrangeiro e colonizador. [...] Civilizada miopia que nos faz ver atraso e ignorância onde há, na verdade, a diferença, a originalidade apaixonante do que não é aquilo que somos nós (SRBEK, 2007, p. 153).

Um paralelo entre a personagem Ulisses e o interlocutor de Riobaldo, em "Grande Sertão: Veredas”, é interessante (sujeito urbano que visita o regional), bem como uma breve referência à biografia de Rosa, um sujeito da cidade, letrado, que experiencia o interior mineiro. Esse Ulisses, sem dúvida, viverá uma aventura - daí a relação com o épico clássico - e tecerá comentários sobre a civilização que observa. No princípio, sua visão é preconceituosa, como evidencia o trecho acima; depois de ser sequestrado por jagunços, salvo por outros jagunços e ouvir muitas versões de histórias, ele muda sua percepção. Sem dúvida, há um tom didático. Saímos do preconceito para a admiração, mas ainda assim, não se 
perde qualidade. Uma vez que o projeto aqui proposta visa a ser aplicado no Ensino Médio, sempre em diálogo com a leitura dos contos de Guimarães, provocar os alunos e levá-los a refletir sobre essa tendência "didática" pode ser interessante. A mediação do professor, mais uma vez, é indispensável, para convidar os alunos a analisar esse recurso narrativo e suas implicações ideológicas. Além disso, essa visão respeitosa do sertão, do interior, dialoga com a postura intelectual e literária de Guimarães, cuja obra abandona o pitoresco - presente no Romantismo - e mergulha na identidade do sertão, valorizando-a e recriando-a.

\section{Comentários finais}

Este breve artigo tece uma proposta de projeto de leitura, tentanto apropriar-se do conceito de letramento literário. A pretensão é demonstrar que nas salas de aula da Educação Básica, quando o assunto é o ensino de literatura, a leitura, o ato de fruição e a discussão devem ser prioridade. Obviamente, nem sempre isso é possível e, acima de tudo, essa postura docente exige muito trabalho - basta verificarmos as etapas propostas por Rildo Cosson. Além de elaborar todas as etapas da atividade, o professor inevitavelmente terá que "convencer" os alunos, argumentando que a leitura é importante, afinal, literatura é arte. As obras canônicas de modo algum devem ser excluídas das salas de aula - até mesmo porque a historiografia, elemento norteador do nosso trabalho didático, não permitiria. Entretanto, a ela podemos agregar leituras mais contemporâneas, diante das quais os alunos não se sintam tão distanciados. Vamos, sim, ler Guimarães Rosa, porém, indispensável é prepararmos os alunos para a leitura e, principalmente, mediarmos essa atividade, para que assim, por meio do letramento literário (isto é, uma aproximação progressiva aos livros), eles possam dialogar com os escritos de Guimarães sem considerá-los uma literatura de impossível compreensão e, nesse sentido, com um aspecto traumático. Um 
bom projeto de leitura, emoldurado a partir dos princípios da Literatura Comparada, pode levar nossos alunos a interagirem com a leitura e com a literatura nacional.

\section{Referências}

CANDIDO, Antonio. O direito à literatura. In: Vários Escritos. São Paulo: Duas Cidades, 1977.

COSSON, Rildo. Letramento literário. São Paulo: Contexto, 2011. COUTINHO, Afrânio. Notas de Teoria Literária. Rio de Janeiro: Vozes, 2008.

GENETTE, Gerárd. Introdução ao arquitexto. Lisboa: Veja, 1990.

JOUVE, Vincent. A leitura. São Paulo: Editora UNESP, 2002.

KRISTEVA, Julia. Introdução à semanálise. São Paulo: Perspectiva, 1974.

RÓNAI, Paulo. Os vastos espaços. In: Primeiras Estórias. Rio de Janeiro: Nova Fronteira, 2005.

ROSA, João Guimarães. Primeiras Estórias. Rio de Janeiro: Nova Fronteira, 2005.

ROSA, João Guimarães. Grande Sertão: veredas. Rio de Janeiro: Nova Fronteira, 2001

SRBEK, Wellington; COLIN, Flavio (ilustração). Estórias Gerais. São Paulo: Conrad, 2007.

ZILBERMAN, Regina; LAJOLO, Marisa (Org.). Leitura em crise na escola: as alternativas do professor. Porto Alegre: Mercado Aberto, 1993. 